\title{
Perioperative Management of Carotid Endarterectomy: A Survey of Clinicians' Backgrounds and Practices
}

\author{
Nathaniel H. Greene, MD,* Mohammed M. Minhaj, MD, ${ }^{*} \dagger$ Ahmed F. Zaky, MD, MPH, ${ }^{*} \dagger$ and Irene Rozet, MD*†
}

Objective: To examine current trends in anesthetic practice for management of carotid endarterectomy (CEA) and how practice may differ by groups of practitioners.

Design: An online survey was sent to the Society of Cardiovascular Anesthesiologists and Society of Neuroscience, Anesthesiology, and Critical Care e-mail list servers. Responses were voluntary.

Setting: Academic medical centers and community-based hospitals providing perioperative care for a CEA in the United States and abroad.

Participants: Anesthesiologists who provide perioperative care for patients undergoing a CEA.

Interventions: None

Measurements and Main Results: Of 664 responders (13\% response rate), most (66\%) had subspecialty training in cardiovascular anesthesiology, had been in practice more than 10 years $(68 \%)$, and practiced in the United States (US, $81 \%$ ). About $75 \%$ of responders considered general anesthesia as a preferable technique for CA, and about $\mathbf{8 9} \%$ of responders provided it in real life, independent of subspecialty training. The most preferable intraoperative neuromonitoring was cerebral oximetry $(28 \%)$, followed by EEG $(24 \%)$, and having an awake patient $(23 \%)$. Neuroprotection

$\mathbf{S}^{\mathrm{T}}$ ROKE REMAINS one of the leading causes of death in the United States, responsible for approximately 134,000 deaths annually. ${ }^{1}$ Carotid artery stenosis is a significant cause of stroke, and the risk of subsequent stroke is related directly to the degree of stenosis. Carotid endarterectomy (CEA) was developed to alleviate surgically correctable atherosclerotic plaque-induced carotid artery stenosis. CEA is still the most frequently performed procedure to treat carotid artery stenosis, although the number of carotid artery stenting procedures has been increasing in the past 10 years. ${ }^{2}$

Despite improvements in surgical technique, CEA carries a relatively high risk of perioperative stroke $(3 \%)$ that seems to double the 4-year mortality rate (from $11 \%$ to $21 \%$ ). ${ }^{2}$ Most perioperative strokes associated with CEA may be preventable. ${ }^{3}$ Despite the availability of various anesthetic techniques for CEA, there is a paucity of research that has specifically addressed the association between anesthetic techniques for CEA and perioperative stroke. A survey completed nearly 20 years ago showed that anesthetic techniques varied greatly between practitioners and could range from regional anesthesia on an awake patient to general anesthesia with time- and resource-intensive neuromonitoring. ${ }^{4}$ Since the time this survey was conducted in 1995, the practice of anesthesiology has changed substantially; more neuromonitors are available, the laryngeal mask airway is more commonly used, and patients undergoing surgery carry more comorbid conditions. Because of the high morbidity and mortality associated with the procedure, it is reasonable to speculate that perioperative outcomes of these patients could improve further, and developing an optimal anesthetic technique could prevent a significant number of complications annually.

The goal of this survey was to measure the variability of anesthetic practice. The authors hypothesized that anesthesiologists, was not considered by $33 \%$ of responders, and upon conclusion of a case, $59 \%$ preferred an awake patient for extubation, while $15 \%$ preferred a deep extubation. Neuroanesthesiologists and non-US responders more often risk stratify patients for perioperative cerebral hyperperfusion syndrome, compared with cardiac anesthesiologists and US responders ( $p=0.004$ and $p<0.005$, respectively). Additionally, reported management strategies vary substantially from anesthetic practice $\mathbf{2 0}$ years ago.

Conclusions: Although there are areas of perioperative management in which there seems to be agreement for the CEA, there are also areas of divergent practice that could represent potential for improvement in overall outcomes. There are many potential reasons to explain divergence in practice by location or subspecialty training, but it remains unclear what the "best practice" may be. Future studies examining outcomes after carotid endarterectomy should include perioperative anesthetic management strategies to help delineate "best practice."

(c) 2014 Elsevier Inc. All rights reserved.

KEY WORDS: carotid endarterectomy, perioperative outcomes, stroke, neuromonitoring

defined by various groups including subspecialty training and location of practice, would have significantly different practice preferences.

\section{METHODS}

This study surveyed practicing anesthesiologists about their practice preferences and surgical characteristics when providing anesthesia for a carotid endarterectomy. A survey of 31 questions regarding the demographic characteristics, professional background of participants, and perioperative anesthetic and surgical management of CEA was built online using the University of Washington Catalyst Web Tools software (the full survey is shown in the Appendix). A link to the survey was sent out to members of the Society of Cardiovascular Anesthesiologists and Society for Neuroscience in Anesthesiology and Critical Care e-mail list servers. Surveys were completed online by all participants anonymously. The survey was available online between June 2012 and December 2012.

In addition to describing overall practice preferences and trends, the survey also was designed to test for differences in practice by subspecialty. Two comparative analyses were conducted: A primary analysis comparing neuroanesthesiologists to cardiac anesthesiologists, and a secondary analysis that separately compared anesthesiologists with subspecialty training and those who were practicing in the US with those without subspecialty training and those who were practicing abroad. Of all the questions asked in the survey, a subset of 5 questions was selected

From the *Department of Anesthesiology and Pain Medicine, University of Washington, Seattle, WA; and †Veteran Affairs, Puget Sound Health Care System, Seattle, WA.

Address reprint requests to Nathaniel H. Greene, MD, $1959 \mathrm{NE}$ Pacific Street, Box 356540, Seattle,WA 98195. E-mail: ngreene@u. washington.edu

(C) 2014 Elsevier Inc. All rights reserved.

1053-0770/2601-0001\$36.00/0

http://dx.doi.org/10.1053/j.jvca.2013.11.007 
to assess for comparisons a priori. Level of significance was adjusted to a Bonferroni adjusted level of 0.01 accordingly. Differences were assessed using chi-squared analysis for binary variables, logistic regression for ordinal variables, and a $t$ test when assuming unequal variances between groups for continuous variables. All analyses were conducted in Stata Intercooled 12 (Statacorp, College Station, TX).

\section{RESULTS}

There were 664 responders out of approximately 5,000 individuals (13\% response rate), all of whom were independently practicing and certified anesthesiologists. An exact number is not known, because both societies provided the investigators with estimates only. Most of the respondents were cardiac anesthesiologists (66\%), were in practice for longer than 10 years $(68 \%)$, and were practicing in the United States (81\%) (Table 1).

Respondents varied greatly in their anesthetic and surgical technical preferences. Most respondents preferred a general to a regional anesthetic for CEA $(75 \% v 25 \%)$ (Table 2). Cerebral oximetry $(28 \%)$ was the preferred neuromonitor among practitioners, followed by EEG and, lastly, maintaining an awake patient (24\% and $23 \%$, respectively). A method of neuroprotection was used by most practitioners (68\%). Most respondents (59\%) preferred an awake extubation rather than a deep extubation (15\%). Considerable variation was noted among practitioners in the preferred technique of airway management for postoperative neck hematoma evacuation. For this postoperative complication, respondents most often preferred an asleep direct laryngoscopy (35\%). Only a minority of respondents never performed risk stratification for cerebral hyperperfusion syndrome before surgery $(40 \%)$.

Perioperative goals of blood pressure management were assessed at 4 time points: Before, during, and after carotid crossclamping, and in the immediate postoperative period in terms of comparisons to baseline blood pressure (Table 3). During clamping, the most common blood pressure goal was at $10 \%$ to $20 \%$ above patient's baseline; before and after clamping, and postoperatively, most respondents preferred to keep blood pressure at the patient's baseline. Beta-blockers were the most commonly used antihypertensive agents in the ICU and floor. Most respondents thought that patients should stay in the hospital and have their blood pressure monitored for 24 to 48 hours postoperatively (Table 1).

Table 1. Study Participants

\begin{tabular}{llrr}
\hline & & $\mathrm{n}$ & $\%$ \\
\hline Subspecialty & Cardiac anesthesiology & 440 & 66.3 \\
& Neuroanesthesiology & 47 & 7.1 \\
& Vascular anesthesiology & 18 & 2.7 \\
& Critical care & 28 & 4.2 \\
& Other & 23 & 3.5 \\
& None & 108 & 16.3 \\
Years in practice & 1-2 years & 40 & 6.0 \\
& 2-5 years & 68 & 10.2 \\
& 5-10 years & 107 & 16.1 \\
Practice setting & P 10 years & 449 & 67.6 \\
& Private practice & 317 & 47.7 \\
& Academic institution & 251 & 37.8 \\
Practice location & Both & 96 & 14.5 \\
& US & 531 & 80.6 \\
& Non-US & 128 & 19.4 \\
\hline
\end{tabular}

Table 2. Survey Responses: Selected Anesthetic Practice Preferences

\begin{tabular}{|c|c|c|}
\hline & $\mathrm{n}$ & $\%$ \\
\hline \multicolumn{3}{|l|}{ Ideal Anesthetic Technique } \\
\hline General & 493 & $75.4 \%$ \\
\hline Regional & 161 & $24.6 \%$ \\
\hline \multicolumn{3}{|l|}{ Preferred Neuromonitor } \\
\hline Transcranial Doppler & 22 & $3.5 \%$ \\
\hline Cerebral oximetry & 178 & $28.3 \%$ \\
\hline EEG & 149 & $23.7 \%$ \\
\hline BIS & 74 & $11.7 \%$ \\
\hline Evoked potentials & 27 & $4.3 \%$ \\
\hline Awake patient & 143 & $22.7 \%$ \\
\hline Stump pressure & 37 & $5.9 \%$ \\
\hline \multicolumn{3}{|l|}{ Intraoperative Neuroprotection* } \\
\hline No neuroprotection & 210 & $32.6 \%$ \\
\hline $100 \%$ oxygen & 219 & $34.0 \%$ \\
\hline Increase in blood pressure & 392 & $60.9 \%$ \\
\hline Sodium thiopental & 21 & $3.3 \%$ \\
\hline Propofol & 62 & $9.6 \%$ \\
\hline Etomidate & 0 & $0.0 \%$ \\
\hline Mannitol & 16 & $2.5 \%$ \\
\hline Hypertonic Saline & 3 & $0.5 \%$ \\
\hline Phenytoin & 3 & $0.5 \%$ \\
\hline \multicolumn{3}{|l|}{ Extubation Technique } \\
\hline Deep extubation & 98 & $14.9 \%$ \\
\hline Awake and following commands & 385 & $58.6 \%$ \\
\hline Delayed extubation in ICU & 3 & $0.5 \%$ \\
\hline No specific extra requirements & 137 & $20.9 \%$ \\
\hline Varies & 34 & $5.2 \%$ \\
\hline \multicolumn{3}{|c|}{ Airway Management of Postoperative Neck Hematoma } \\
\hline Awake fiberoptic intubation & 151 & $23.3 \%$ \\
\hline Asleep fiberoptic intubation & 12 & $1.8 \%$ \\
\hline Awake direct laryngoscopy & 47 & $7.2 \%$ \\
\hline Asleep direct laryngoscopy & 230 & $35.4 \%$ \\
\hline Awake video laryngoscopy & 85 & $13.1 \%$ \\
\hline Asleep video laryngoscopy & 119 & $18.3 \%$ \\
\hline LMA or supraglottic device & 5 & $0.8 \%$ \\
\hline \multicolumn{3}{|c|}{ Risk Stratification of Cerebral Hyperperfusion Syndrome } \\
\hline Routinely & 102 & $15.5 \%$ \\
\hline Occasionally & 129 & $19.7 \%$ \\
\hline Rarely & 166 & $25.3 \%$ \\
\hline Never & 259 & $39.5 \%$ \\
\hline
\end{tabular}

*More than one choice allowed

Table 4 illustrates the primary analysis. Although there were measured differences between individuals who identified themselves as neuroanesthesiologists or cardiac anesthesiologists, the only statistically significant difference was with risk stratification of patients for cerebral hyperperfusion syndrome $(p=0.004)$. There was a trend toward a difference between these 2 groups in optimal anesthetic technique, with $30 \%$ of neuroanesthesiologists versus $22 \%$ of cardiac anesthesiologists preferring a regional technique and $6 \%$ of neuroanesthesiologists versus $15 \%$ of cardiac anesthesiologist preferring deep extubation, although these comparisons did not reach statistical significance $(\mathrm{p}=0.231$ and 0.100 , respectively).

Table 4 also shows the secondary analysis, which compares anesthesiologists with a claimed subspecialty with those without and compares anesthesiologists practicing in the US with those practicing outside the US. The only measured difference 
Table 3. Survey Responses: Perioperative Blood Pressure Management

\begin{tabular}{|c|c|c|c|c|c|c|c|}
\hline $\begin{array}{l}\text { Perioperative Blood Pressure } \\
\text { Goals }\end{array}$ & $\begin{array}{l}\text { At Patient's } \\
\text { Baseline (\%) }\end{array}$ & $\begin{array}{c}10 \%-20 \% \text { Above } \\
\text { Patient's Baseline (\%) }\end{array}$ & $\begin{array}{c}\text { 10\%-20\% Below } \\
\text { Patient's Baseline (\%) }\end{array}$ & $\begin{array}{c}\text { Systolic BP }>140 \\
\mathrm{mmHg}(\%)\end{array}$ & $\begin{array}{c}\text { Systolic BP }<110 \\
\mathrm{mmHg}(\%)\end{array}$ & $\begin{array}{c}\text { No Specific } \\
\text { Goals }(\%)\end{array}$ & $\begin{array}{c}\text { Varies } \\
(\%)\end{array}$ \\
\hline $\begin{array}{l}\text { BP goal before carotid } \\
\text { cross-clamping }\end{array}$ & 54.8 & 22.2 & 11.1 & 5.2 & 0.3 & 3.5 & 3.0 \\
\hline $\begin{array}{l}\text { BP goal during carotid } \\
\text { cross-clamping }\end{array}$ & 19.5 & 61.4 & 2.6 & 8.8 & 0.6 & 2.1 & 5.0 \\
\hline $\begin{array}{l}\text { BP goal after carotid cross- } \\
\text { clamping }\end{array}$ & 49.5 & 8.0 & 28.5 & 2.4 & 2.0 & 3.2 & 6.3 \\
\hline $\begin{array}{l}\text { BP goal immediately } \\
\text { postoperatively }\end{array}$ & 52.6 & 7.5 & 28.4 & 3.7 & 2.6 & 5.2 & 0.0 \\
\hline $\begin{array}{l}\text { Perioperative Blood } \\
\text { Pressure Agents }\end{array}$ & $\begin{array}{c}\text { Beta } \\
\text { Blocker (\%) }\end{array}$ & $\begin{array}{l}\text { Hydralazine } \\
(\%)\end{array}$ & $\begin{array}{l}\text { Nitroglycerin } \\
(\%)\end{array}$ & $\begin{array}{l}\text { Nitroprusside } \\
(\%)\end{array}$ & $\begin{array}{l}\text { Calcium Channel } \\
\text { Blocker }(\%)\end{array}$ & $\begin{array}{l}\text { ACE Inhibitor } \\
(\%)\end{array}$ & \\
\hline $\begin{array}{l}\text { ICU first choice BP } \\
\text { control agent }\end{array}$ & 53.9 & 3.9 & 15.3 & 9.9 & 16.6 & 0.4 & \\
\hline $\begin{array}{l}\text { Ward first choice BP } \\
\text { control agent }\end{array}$ & 73.6 & 6.4 & 3.0 & 0.4 & 10.7 & 5.8 & \\
\hline $\begin{array}{l}\text { Postoperative Blood } \\
\text { Pressure Monitoring }\end{array}$ & $\begin{array}{l}<24 \text { Hours } \\
(\%)\end{array}$ & $\begin{array}{l}\text { 24-48 Hours } \\
(\%)\end{array}$ & $\begin{array}{l}\text { 48-96 Hours } \\
(\%)\end{array}$ & $\begin{array}{c}>96 \text { Hours } \\
(\%)\end{array}$ & & & \\
\hline $\begin{array}{l}\text { Recommended } \\
\text { Postoperative stay }\end{array}$ & 20.9 & 66.1 & 12.0 & 0.9 & & & \\
\hline $\begin{array}{l}\text { Recommended } \\
\text { Postoperative BP } \\
\text { Monitoring }\end{array}$ & 34.8 & 59.4 & 5.5 & 0.3 & & & \\
\hline
\end{tabular}

Abbreviations: $\mathrm{ACE}$, angiotensin converting enzyme; $\mathrm{BP}$, blood pressure.

in those with a claimed subspecialty was the practice of risk stratification for cerebral hyperperfusion syndrome, with the practice being less common among those without a claimed subspecialty $(\mathrm{p}=0.001)$. There seemed to be more differences between anesthesiologists practicing in the US compared with those practicing outside the US. More non-US anesthesiologists practiced risk stratification for cerebral hyperperfusion syndrome $(\mathrm{p}<0.0005)$, and there was a trend toward preferring a regional anesthetic $(\mathrm{p}=0.073)$ and deep extubation $(\mathrm{p}=0.054)$, although these results were not statistically significant.

\section{DISCUSSION}

This study showed substantial variability in the conduct of anesthesia for CEA among practicing anesthesiologists, some of which might be explained by their background and clinical training. The main areas of disagreement tended to be in perioperative blood pressure management, risk stratification for cerebral hyperperfusion syndrome, and intraoperative neuromonitoring.

The results of this survey also reflected, substantial differences when compared with the last survey done 18 years ago. Since the time of the last survey, ${ }^{4} 3$ surgical societies have reported guidelines for this procedure, ${ }^{5-7}$ and clinicians have the results of a very large randomized controlled trial examining local anesthesia versus general anesthesia (the GALA trial), which did not seem to show any significant differences between the 2 techniques. ${ }^{8}$ Anesthesiologists still seem to prefer general anesthesia for this procedure, but methods for neuromonitoring and neuroprotection have changed substantially. EEG used to be the

Table 4. Comparisons Between Groups: Statistical Analysis

\begin{tabular}{|c|c|c|c|c|c|c|c|c|c|c|}
\hline \multirow[b]{2}{*}{ Question } & \multirow[b]{2}{*}{ Answer } & \multicolumn{3}{|c|}{ Primary Analysis } & \multicolumn{6}{|c|}{ Secondary Analysis } \\
\hline & & Neuro & Cardiac & $\mathrm{p}$ Value & None & Fellowship & $\mathrm{p}$ Value & US & Non-US & $\mathrm{p}$ Value \\
\hline Better anesthetic technique & $\%$ regional (vs. general) & $30 \%$ & $22 \%$ & 0.231 & $21 \%$ & $25 \%$ & 0.371 & $23 \%$ & $31 \%$ & 0.073 \\
\hline Anesthetic actually provided & $\%$ general (vs. regional) & $89.8 \%$ & $87.8 \%$ & $0.648^{*}$ & $87.5 \%$ & $87.3 \%$ & $0.931^{*}$ & $89.1 \%$ & $77.7 \%$ & $0.003^{*}$ \\
\hline \multirow[t]{4}{*}{ Risk stratify patients $\mathrm{CHS}$} & Routinely & $30 \%$ & $14 \%$ & $0.004^{\dagger}$ & $7 \%$ & $17 \%$ & $0.001^{\dagger}$ & $13 \%$ & $26 \%$ & $<0.0005^{\dagger}$ \\
\hline & Occasionally & $17 \%$ & $22 \%$ & & $11 \%$ & $21 \%$ & & $17 \%$ & $32 \%$ & \\
\hline & Rarely & $33 \%$ & $24 \%$ & & $27 \%$ & $25 \%$ & & $26 \%$ & $23 \%$ & \\
\hline & Never & $20 \%$ & $40 \%$ & & $54 \%$ & $37 \%$ & & $45 \%$ & $18 \%$ & \\
\hline BP goal during clamping & $\begin{array}{l}\% \text { above baseline ( } v \text { at baseline or } \\
\text { below baseline or other choice) }\end{array}$ & $57 \%$ & $62 \%$ & 0.558 & $59 \%$ & $62 \%$ & 0.660 & $62 \%$ & $59 \%$ & 0.483 \\
\hline $\begin{array}{l}\text { Preferable extubation } \\
\text { technique }\end{array}$ & $\%$ Deep extubation ( $v$ other choice) & $6 \%$ & $15 \%$ & 0.100 & $17 \%$ & $14 \%$ & 0.541 & $14 \%$ & $20 \%$ & 0.054 \\
\hline
\end{tabular}

NOTE. All other $\mathrm{p}$ values calculated using chi-squared analysis.

Abbreviations: $\mathrm{BP}=$ blood pressure; $\mathrm{CHS}$, cerebral hyperperfusion syndrome.

*Calculated from two group 2-sided $t$ test assuming unequal variance.

tCalculated using ordinal logistic regression. 
most commonly used monitor, and now practice is much more variable, with cerebral oximetry being used as the most common neuromonitor. Neuroprotection is now used by $68 \%$ of anesthesiologists today compared with $22 \%$ of anesthesiologists in 1995, and although previously the most common method of neuroprotection, barbiturates rarely are used now.

Fellowship training seems to be a potential cause of variation in practice as well as practice location. Neuroanesthesiologists, compared with cardiac anesthesiologists, were more likely to risk stratify a patient for the development of cerebral hyperperfusion syndrome, ${ }^{9,10}$ a rare but devastating complication after CEA that can cause hemorrhagic stroke and subsequent death. They also trended toward preferring an awake extubation. Given the focus of their subspecialty training, this is predictable, considering that neuroanesthesiologists might focus more on brain perfusion and autoregulation while cardiac anesthesiologists might focus more on cardiac perfusion and preventing myocardial ischemia. When comparing those with fellowship training to those without, the only notable difference was how often risk stratification was undertaken for cerebral hyperperfusion syndrome. This may be a reflection of patient disease or whether or not patients are taken care of in academic medical centers where risk stratification procedures can be obtained easily. Anesthesiologists practicing in the US tended to do fewer deep extubations, prefer and perform more general anesthetics, and risk stratify for cerebral hyperperfusion syndrome less often. These differences probably are based on localized training practices, but also may be reflective of surgeon preferences in the United States and elsewhere.

The limitations of this survey should be considered when interpreting the results of the survey. This survey was sent out only to those on select subspecialty anesthesiology e-mail lists, which is not representative of all anesthesiologists providing care for CEA procedures. Despite this fact, it is reasonable to predict variation in care among those not included in the survey, because such a high degree of variation was seen in those to whom the survey was sent. Also, the response rate was lower than anticipated; thus, results were interpreted assuming that the likelihood of an anesthesiologist to respond to a survey is not associated with any particular practice preference, which the authors believe to be a reasonable assumption. As surveys in anesthesiology are moving to be online instead of mail based, lower response rates are seen, ${ }^{11,12}$ and a recent review of the online survey methodology suggests that sending reminders to complete surveys will not change the outcome of survey findings. ${ }^{13}$ Most responders were anesthesiologists with cardiac fellowship training, but it may be true that this case is typically assigned to an anesthesiologist with cardiac fellowship training because these patients usually share similar pathophysiology to those undergoing cardiac surgical procedures. Additionally, respondents were asked in the survey if they had a particular subspecialty, and the answer to this question was used as an indicator of subspecialty training. It is likely that if a particular respondent selected a subspecialty, then they would be still often providing anesthetics in a particular specialty area and would have similar behaviors to others in the specialty. It should also be noted that this was a survey of providers' practice preferences and not patient outcomes. This data should not be used to advise anesthetic practice but, hopefully, will inspire future outcome-based studies.

Future prospective studies that focus on outcomes based on anesthetic technique likely will help decrease the observed variation in this survey. Without such evidence, it is difficult to strongly support one method of practice over another. Only well-designed research will change long-held practice preferences, but it is clear this is a topic worthy of future inquiry given the variation observed and the considerable morbidity associated with this procedure.

\section{REFERENCES}

1. Minino AM, Murphy SL, Xu J, et al: Deaths: Final data for 2008. Natl Vital Stat Rep 59:1-126, 2011

2. Furie KL, Kasner SE, Adams RJ, et al: Guidelines for the prevention of stroke in patients with stroke or transient ischemic attack: A guideline for healthcare professionals from the American Heart Association/ American Stroke Association. Stroke 42:227-276, 2011

3. Hill MD, Brooks W, Mackey A, et al: Stroke after carotid stenting and endarterectomy in the Carotid Revascularization Endarterectomy versus Stenting Trial (CREST). Circulation 126:3054-3061, 2012

4. Cheng MA, Theard MA, Tempelhoff R: Anesthesia for carotid endarterectomy: A survey. J Neurosurg Anesthesiol 9:211-216, 1997

5. Biller J, Feinberg WM, Castaldo JE, et al: Guidelines for carotid endarterectomy: A statement for healthcare professionals from a Special Writing Group of the Stroke Council, American Heart Association. Circulation 97:501-509, 1998

6. Liapis CD, Bell PR, Mikhailidis D, et al: ESVS guidelines. Invasive treatment for carotid stenosis: indications, techniques. Eur J Vasc Endovasc Surg 37:1-19, 2009

7. Brott TG, Halperin JL, Abbara S, et al: 2011 ASA/ACCF/AHA/ AANN/AANS/ACR/ASNR/CNS/SAIP/SCAI/SIR/SNIS/SVM/SVS guideline on the management of patients with extracranial carotid and vertebral artery disease. Stroke 42:e464-e540, 2011

8. Lewis SC, Warlow CP, Bodenham AR, et al: General anaesthesia versus local anaesthesia for carotid surgery (GALA): A multicentre, randomised controlled trial. Lancet 372:2132-2142, 2008

9. Moulakakis KG, Mylonas SN, Sfyroeras GS, et al: Hyperperfusion syndrome after carotid revascularization. J Vasc Surg 49:1060-1068, 2009

10. Bouri S, Thapar A, Shalhoub J, et al: Hypertension and the postcarotid endarterectomy cerebral hyperperfusion syndrome. Eur J Vasc Endovasc Surg 41:229-237, 2011

11. Lirk P, Rutten MV, Haller I, et al: Management of the patient with diabetic peripheral neuropathy presenting for peripheral regional anesthesia: A European survey and review of literature. Minerva Anestesiol 79:1039-1048, 2013

12. Rafique MB, Cameron SD, Khan Q, et al: Anesthesia for children with mitochondrial disorders: A national survey and review. J Anesth 27:186-191, 2013

13. Dykema J, Jones NR, Piche T, et al: Surveying clinicians by web: Current issues in design and administration. Eval Health Prof 36: 352-381, 2013 